\title{
Hepatoprotective effects of methanol leaf extract of Pterocarpus santalinoides DC on acetaminophen-induced liver damage in Albino rats (Rattus norvegicus) \\ ${ }^{* 1}$ Ihedioha, T. E., 'Onwuegbuka, L. U. and ${ }^{2}$ Ihedioha, J. I. \\ ${ }^{I}$ Departments of Veterinary Physiology \& Pharmacology, Faculty of Veterinary Medicine, University of Nigeria, Nsukka, Enugu State, Nigeria. \\ ${ }^{2}$ Department of Veterinary Pathology \& Microbiology, Faculty of Veterinary Medicine,

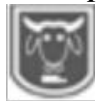 \\ Abstract University of Nigeria, Nsukka, Enugu State, Nigeria. *Correspondence author. E-mail: thelma.ihedioha@unn.edu.ng Phone number: +2348036868258
}

The effects of methanol leaf extract of Pterocarpus santalinoides DC was investigated on acetaminophen (APAP)-induced sub-acute liver damage (hepatotoxicity) in albino rats. Forty two adult male albino rats were used for the study, 12 for the acute toxicity study and 30 for the sub-acute hepatotoxicity study. The 30 rats used for the sub-acute hepatotoxicity study were randomly assigned into six groups $(A-F)$ of 5 rats each as follows: Group $A-$ $A P A P+$ distilled water placebo (negative control), Groups $B, C$ and $D-A P A P+50,250$, and $500 \mathrm{mg} / \mathrm{kg}$ body weight (bw) Pterocarpus santalinoides methanol extract (PSME) respectively, Group E-APAP + $100 \mathrm{mg} / \mathrm{kg}$ bw silymarin (positive control), and Group Fdistilled water placebo only (normal control). The APAP was given at $3000 \mathrm{mg} / \mathrm{kg} \mathrm{bw}$ orally at the beginning of the study (day 0 ) and after every 72 hours for 12 days, while treatment with PSME and silymarin was done orally twice daily for 15 days. Phytochemical analysis and acute toxicity evaluation followed standard procedures. Assay of serum enzymes, total serum protein, albumin, globulin, total cholesterol and bilirubin, and liver weight percentage of body weight of the rats was done at the end of the 15-day experimental period following standard procedures. The PSME had high levels of tannins, moderate levels of flavonoids, saponins, carbohydrates and reducing sugars, and low levels of alkaloids. The $L D_{50}$ was above $5000 \mathrm{mg} / \mathrm{kg} \mathrm{bw}$. Treatment with PSME at the dose of $500 \mathrm{mg} / \mathrm{kg} \mathrm{bw}$ significantly lowered $(P<0.05)$ serum ALT, AST, and ALP activities, cholesterol and bilirubin levels, and liver weight percentage of body weight when compared to the negative control, while treatment at the dose of $250 \mathrm{mg} / \mathrm{kg}$ bw only led to significantly lower $(P<0.05)$ serum levels of cholesterol and bilirubin when compared to the negative control. It was concluded that treatment of acetaminophen-induced sub-acute hepatotoxicity in albino rats with $500 \mathrm{mg} / \mathrm{kg}$ bw PSME significantly protected the hepatocellular integrity and ameliorated impaired hepatic excretory function.

Key words: Hepatoprotection, Pterocarpus santalinoides, methanol leaf extract.

\section{Introduction}

The liver is a vital organ responsible for the detoxification of various drugs and xenobiotics in the body (Singh et al., 2012). The central role the liver plays in the clearance and transformation of chemicals is documented (Singh et al., 2011). Chemicals that cause liver injury (hepatotoxicants and/or hepatotoxins) include a wide variety of pharmaceutical agents, natural products, industrial chemicals, microbial toxins, environmental pollutants, herbal remedies and dietary supplements (Willett et al., 2004; Papay et al., 2009). Hepatotoxicity-induced disorders are reversible at early stages upon cessation of exposure to the hepatotoxicants. However, severe 


\section{Hepatoprotective effects of $P$. santalinoides extract.}

intoxication with these hepatotoxicants can lead to liver necrosis and death of the organism if left untreated (Schiff and Schiff, 1987). Despite various hepatoprotective drugs and herbal treatments available today, therapy for liver disease remains unsatisfactory and inadequate (Singh et al., 2012). Moreover, increasing incidence of xenobiotic-induced hepatotoxicity has become a driving force behind the search for more promising and possibly better hepatoprotective therapies.

Pterocarpus santalinoides DC is an indigenous Nigerian plant in the family Papilionaceae. It is commonly referred to as "Red Sandal wood" in English (Anowai et al., 2012), and locally, it is known as nturukpa in Igbo, gunduru, gyadar, or kurmi in Hausa, gbengbe in Yoruba, akumeze in Edo, nja in Efik, kereke in Tiv, and maganchi in Nupe. The Leaves of $P$. santalinoides are traditionally used as food (vegetable) and as medicine in the treatment of various ailments which includes diarrhoea and vomiting, dysentery, elephantiasis, malaria, cold, cough, and liver diseases (Adesina, 1982). Scientific reports on the medicinal use of the leaves of $P$. santalinoides for the treatment of liver diseases is however lacking in available scientific literature. The objective of this study therefore was to evaluate the effects of methanol leaf extract of $P$. santalinoides DC on acetaminophen-induced liver damage in albino rats.

\section{Materials and Methods}

Fresh leaves of $P$. santalinoides used for the study were collected in February 2016 from Nsukka, Enugu state, Nigeria. The plant was identified by a plant taxonomist at the Department of Plant Science and Biotechnology, University of Nigeria, Nsukka Voucher Specimen Number - UNH No. 02). The leaves were dried under shade for two weeks, pulverized, and ground into powder. Five hundred $(500 \mathrm{~g})$ of the powdered leaves was extracted with absolute methanol using the cold maceration technique. The resulting extract was filtered using Whatmann size 1 filter paper, concentrated to dryness with a rotary evaporator, and resulting product referred to as Pterocarpus santalinoides methanol extract (PSME). Phytochemical analysis was carried out on PSME following the standard procedure described by Harborne (1998).

Forty two (42) adult male albino rats (Rattus norvegicus) of 12 weeks of age weighing between $250 \mathrm{~g}-300 \mathrm{~g}$, were obtained from the Laboratory Animal UnitDepartment of Veterinary Physiology and Pharmacology, University of Nigeria, Nsukka, and used for the study. The albino rats were housed in stainless steel cages in a fly proof animal house at room temperature $\left(27^{\circ}\right)$, and allowed 2 weeks to acclimatize before the commencement of the study. The rats were fed commercial pelletized feed (Grand Cereals Ltd, Jos, Nigeria), and were provided with clean water ad libitum for 30 days. Twelve of the albino rats were used for acute toxicity test, and median lethal dose $\left(\mathrm{LD}_{50}\right)$ of the extract was determined following thenew approach to practical acute toxicity testing as described by Lorke (1983). The remaining thirty (30) male albino rats were used for the sub-acute hepatotoxicity study. They were randomly assigned into six (6) groups (A, B, C, D, E and F) of five rats each. Groups A, B, C, D, and $\mathrm{E}$ were given $3000 \mathrm{mg} / \mathrm{kg}$ bw acetaminophen orally at the beginning of the experiment (day 0), and after every 72 hours for 12 days (days 0, 3, 6, 9 and 12). Treatment with PSME was done per os twice daily for 15 days as follows: group A served as negative control (given acetaminophen and treated with $10 \mathrm{ml} / \mathrm{kg}$ 


\section{Ihedioha, Onwuegbuka and Ihedioha}

bw distilled water placebo), groups $\mathrm{B}, \mathrm{C}$ and $\mathrm{D}$ were given acetaminophen and treated with 50,250 , and $500 \mathrm{mg} / \mathrm{kg}$ bw PSME respectively, group $\mathrm{E}$ was given acetaminophen and treated with silymarin (a standard hepatoprotective drug) at the dose of $100 \mathrm{mg} / \mathrm{kg}$ bw per os twice daily as positive control, while group $\mathrm{F}$ was not given acetaminophen and was treated with $10 \mathrm{ml} / \mathrm{kg}$ bw of distilled water placebo and served as normal control. Blood samples were collected from the albino rats on day 15 (at the end of the experiment) for serum biochemistry assay. Blood sample collection was by the orbital technique (Bolliger \& Everds, 2010), while the serum biochemistry assay was done immediately upon separation of the serum from blood clot, following standard procedures (Colville, 2002) using Quimica Clinica Applicada (QCA) test kits (QCA, Spain). The serum enzymes and biochemicals evaluated were alanine aminotransferase (ALT), aspartate aminotransferase (AST), alkaline phosphatase (ALP), total cholesterol, total bilirubin, total proteins, albumin and globulin. The rats were humanely sacrificed afterwards on the $15^{\text {th }}$ day by a single intra-peritoneal injection of $200 \mathrm{mg} / \mathrm{kg}$ of thiopentone sodium (AVMA, 2013). They were dissected and their livers harvested. The liver weights were measured, and relative liver weight of individual rat was calculated. The handling, management and use of the albino rats in this experiment were in conformity with the Guide to Humane Laboratory Animal Use (NRC, 1985).

\section{Statisticalanalysis}

Data obtained from the study were subjected to one way analysis of variance (ANOVA), and variant means were separated post hoc using the least significant difference (LSD) method. Significance was accepted at $\mathrm{p}<0.05$.

\section{Results and Discussion}

The PSME was dark green and soluble in water. The percentage yield was $18 \% \mathrm{w} / \mathrm{w}$. The phytochemical analysis carried out on PSME showed the presence of high levels $(+++)$ of tannins, moderate levels (++) of flavonoids, saponins, carbohydrates and reducing sugars and low levels (+) of alkaloids. These phytochemicals are essential compounds commonly found in various herbs used for medicinal purposes. Phytochemicals similar and comparable to the ones recorded in this study had also been reported by Anowai et al. (2012), Eze et al. (2012) and Odeh et al. (2014) in the ethanol extracts of the leaf and stem bark of $P$. santalinoides.

The acute toxicity test showed that there was no mortality or any obvious sign of toxicity in all the rats treated with PSME, and that the $\mathrm{LD}_{50}$ is above $5000 \mathrm{mg} / \mathrm{kg}$ bw. This result places PSME within the World Health Organization's (WHO) category of substances "unlikely to present acute hazard in normal use" (WHO, 2001). This implies that the methanolic leaf extract of $P$. santalinoides is safe for acute use as treatment of ailments and diseases for which it is effective. This finding is in agreement with the reports of Anowai et al. (2012) and Eze et al. (2012) on $P$. santalinoides leaf and stem bark extracts, respectively.

The serum ALT activity of rats in groups A, $\mathrm{B}$ and $\mathrm{C}$ were significantly higher $(\mathrm{P}<0.05)$ than and ranged from two to three times that of groups D, E and F, while the serum AST activity of groups A and B were significantly higher $(\mathrm{P}<0.05)$ and almost two times those of groups D, E and F (Table 1 ). The serum ALP activity of rats in groups A, B, C, D and E were significantly higher $(\mathrm{P}<0.05)$ than, and ranged from two to three times that of group $\mathrm{F}$ rats, though that 


\section{Hepatoprotective effects of P. santalinoides extract.}

of groups $\mathrm{D}$ and $\mathrm{E}$ were significantly lower $(\mathrm{P}<0.05)$ than those of groups A, B and C (Table 1). The serum total cholesterol levels of group A rats were significantly lower $(\mathrm{P}<0.05)$ than those of group C, D, E and $\mathrm{F}$ rats, while the serum bilirubin levels of rats in groups A and B were about two times those of rats in groups $\mathrm{D}, \mathrm{E}$ and $\mathrm{F}$, and was found to be significantly higher $(\mathrm{P}<$ 0.05 ) than those of groups $\mathrm{C}, \mathrm{D}, \mathrm{E}$ and $\mathrm{F}$ (Table 1).

Table 1. Effects of oral administration of PSME on serum enzymes activity, cholesterol and bilirubin levels of rats given sub-acute toxic doses of acetaminophen (APAP)

\begin{tabular}{lccccc}
\hline & & \multicolumn{4}{c}{ Mean \pm standard error } \\
Groups & ALT (U/L) & AST (U/L) & ALP (U/L) & TChol. (mg/dl) & TBil. (mg/dl) \\
\hline Group A & $96.38 \pm 4.79^{\mathrm{a}}$ & $108.43 \pm 6.83^{\mathrm{a}}$ & $345.16 \pm 43.27^{\mathrm{a}}$ & $78.23 \pm 6.87^{\mathrm{a}}$ & $0.64 \pm 0.04^{\mathrm{a}}$ \\
Group B & $89.74 \pm 6.86^{\mathrm{a}}$ & $106.94 \pm 7.02^{\mathrm{a}}$ & $363.21 \pm 30.67^{\mathrm{a}}$ & $68.74 \pm 8.28^{\mathrm{ab}}$ & $0.58 \pm 0.06^{\mathrm{a}}$ \\
Group C & $72.43 \pm 5.37^{\mathrm{a}}$ & $83.24 \pm 6.44^{\mathrm{ab}}$ & $339.83 \pm 29.42^{\mathrm{a}}$ & $63.44 \pm 3.76^{\mathrm{b}}$ & $0.43 \pm 0.05^{\mathrm{b}}$ \\
Group D & $46.32 \pm 4.28^{\mathrm{b}}$ & $61.11 \pm 5.23^{\mathrm{b}}$ & $286.33 \pm 30.26^{\mathrm{b}}$ & $59.25 \pm 4.21^{\mathrm{b}}$ & $0.32 \pm 0.04^{\mathrm{c}}$ \\
Group E & $43.65 \pm 5.02^{\mathrm{b}}$ & $62.43 \pm 4.79^{\mathrm{b}}$ & $256.39 \pm 18.21^{\mathrm{b}}$ & $64.32 \pm 5.43^{\mathrm{b}}$ & $0.30 \pm 0.04^{\mathrm{c}}$ \\
Group F & $33.66 \pm 4.73^{\mathrm{b}}$ & $57.29 \pm 5.03^{\mathrm{b}}$ & $105.28 \pm 24.23^{\mathrm{c}}$ & $61.77 \pm 3.48^{\mathrm{b}}$ & $0.31 \pm 0.05^{\mathrm{c}}$ \\
\hline
\end{tabular}

[ALT $=$ Alanine aminotransferase; AST $=$ Aspartate aminotransferase; ALP $=$ Alkaline phosphatase;

TChol. $=$ Total Cholesterol; TBil. $=$ Total bilirubin $]$

Alphabetical superscripts in a column indicate significant differences between the groups, $\mathrm{p}<0.05$.

* Group treatments: Group A - APAP + distilled water placebo; Group B - APAP + 50mg/kg bw of PSME; Group C - APAP + 250mg/kg bw of PSME; Group D - APAP + 500mg/kg bw of PSME; Group E = APAP $+100 \mathrm{mg} / \mathrm{kg}$ bw Silymarin; Group F - Distilled water placebo only.

The significantly higher serum enzyme activity of ALT, AST and ALP, and higher serum levels of cholesterol and bilirubin in the group A rats and some others that were given acetaminophen and treated are indicators of the ability of acetaminophen to induce liver damage by disrupting hepatocellular integrity and liver function (Sun et al., 2009). The finding in this study that rats in group D which were given acetaminophen and treated with $500 \mathrm{mg} / \mathrm{kg}$ bw PSME had serum ALT, AST and ALP activities significantly lower than that of group A and comparable to that recorded for groups $E$ and $F$ implied that the administration of PSME at the dose of 500 $\mathrm{mg} / \mathrm{kg}$ bw was protective of the hepatocellular integrity of the liver and compared effectively with silymarin (a standard hepatoprotective drug). This finding is in agreement with the reports of
Offor et al. (2015) who studied the effects of ethanol leaf extract of the plant on liver enzymes. The significantly higher serum total cholesterol (TC) of rats in group A, and total bilirubin of rats in groups A and $\mathrm{B}$ when compared to other groups is an indication that the excretory function of the liver of rats that were given acetaminophen were impaired, and that treatment with PSME ameliorated the impairment. There were no significant variations $(\mathrm{P}>$ 0.05 ) in the levels of serum proteins and albumins between the rat groups, but serum globulin levels of rats in group A and B were significantly lower $(\mathrm{P}<0.05)$ than that of the group $\mathrm{F}$ rats (Table 2). The liver weight percentage of body weight of rats in groups A and B were however significantly higher $(\mathrm{P}<0.05)$ than those of rats in groups $\mathrm{D}, \mathrm{E}$ and $\mathrm{F}$ (Table 2). 


\section{Ihedioha, Onwuegbuka and Ihedioha}

Table 2. Effects of oral administration of PSME on serum proteins and liver weight percentage of body weight of rats given sub-acute toxic doses of acetaminophen (APAP)

\begin{tabular}{ccccc}
\hline Groups & $\begin{array}{c}\text { Total proteins } \\
(\mathrm{g} / \mathrm{dl})\end{array}$ & $\begin{array}{c}\text { Albumins } \\
(\mathrm{g} / \mathrm{dl})\end{array}$ & $\begin{array}{c}\text { Globulins } \\
(\mathrm{g} / \mathrm{dl})\end{array}$ & $\begin{array}{c}\text { Liver weight } \% \text { of } \\
\text { body weight }(\%)\end{array}$ \\
\hline Group A & $7.03 \pm 0.32$ & $3.20 \pm 0.18$ & $3.82 \pm 0.12^{\mathrm{a}}$ & $4.53 \pm 0.18^{\mathrm{a}}$ \\
Group B & $7.01 \pm 0.27$ & $3.27 \pm 0.20$ & $3.75 \pm 0.16^{\mathrm{a}}$ & $4.37 \pm 0.14^{\mathrm{a}}$ \\
Group C & $7.25 \pm 0.18$ & $3.32 \pm 0.14$ & $3.93 \pm 0.15^{\mathrm{ab}}$ & $4.29 \pm 0.12^{\mathrm{ab}}$ \\
Group D & $7.36 \pm 0.20$ & $3.34 \pm 0.18$ & $4.01 \pm 0.17^{\mathrm{ab}}$ & $4.11 \pm 0.14^{\mathrm{b}}$ \\
Group E & $7.41 \pm 0.19$ & $3.38 \pm 0.16$ & $4.02 \pm 0.16^{\mathrm{ab}}$ & $4.02 \pm 0.19^{\mathrm{b}}$ \\
Group F & $7.43 \pm 0.21$ & $3.36 \pm 0.12$ & $4.07 \pm 0.15^{\mathrm{b}}$ & $3.93 \pm 0.24^{\mathrm{b}}$ \\
\hline
\end{tabular}

Alphabetical superscripts in a column indicate significant differences between the groups, $\mathrm{p}<0.05$.

* Group treatments: Group A - APAP + distilled water placebo; Group B - APAP + 50mg/kg bw of PSME; Group C - APAP + 250mg/kg bw of PSME; Group D - APAP + 500mg/kg bw of PSME; Group E = APAP $+100 \mathrm{mg} / \mathrm{kg}$ bw Silymarin; Group F - Distilled water placebo only.

The lack of significant variation between the rat groups in their serum levels of total proteins and albumins indicates that subacute administration of acetaminophen as used in the study did not significantly affect the protein synthetic function of the liver. The significantly lower serum globulin levels of the group A rats when compared to group $\mathrm{F}$ rats may be attributed to the negative effects of acetaminophen on other body organs (including the lymphoid organs) apart from the liver (Sun et al., 2009). The higher liver weight percentage of body weight of rats in groups A and B is an indication of inflammation and/or degeneration which accompanies hepatotoxicity (Saukkonen et al., 2006; Sun et al., 2009). Treatment with PSME at 500 $\mathrm{mg} / \mathrm{kg}$ bw and silymarin at $100 \mathrm{mg} / \mathrm{kg}$ bw significantly reduced this inflammation/degeneration induced enlargement caused by acetaminophen toxicity.

\section{Conclusion}

The treatment of acetaminophen-induced hepatic injury in albino rats with the $P$. santalinoides methanol leaf extract (PSME) at the dose of $500 \mathrm{mg} / \mathrm{kg}$ bw led to significantly lower $(\mathrm{P}<0.05)$ serum ALT, AST, and ALP activity, cholesterol and bilirubin levels, and liver weight percentage of body weight of the treated rats when compared to the negative control. Also treatment with PSME at $250 \mathrm{mg} / \mathrm{kg}$ bw and $500 \mathrm{mg} / \mathrm{kg}$ bw led to significantly lower (P $<0.05$ ) serum levels of total cholesterol and bilirubin of the treated rats when compared to the negative control. These results substantiate the validity of the traditional use of the leaves of $P$. santalinoides in the treatment of liver diseases, and also strongly suggest that the methanolic leaf extract of $P$. santalinoides can be safely used for the treatment of sub-acute toxic liver injury.

\section{References}

Adesina, S.K. (1982). Studies on Nigerian herbal medicinal plants. Int. J. Crude Drug Res. 20(2): 93-100.

Anowai, C.F., Okonkwo, C.C.A and Agbata, E.E. (2012). Preliminary phytochemical screening, evaluation of acute toxicity and antipyretic activity of methanolic extract of Pterocarpus santalinoides (Fabaceae). Int. J. Pharm. Phytopharmacol. Res. 1(6):343-346.

AVMA (2013). Guidelines for the Euthanasia of Animals, 2013 


\section{Hepatoprotective effects of $P$. santalinoides extract.}

Edition. American Veterinary Medical Association, Illinois, USA.

Bolliger, A.P., Everds, N.E. (2010). Hematology of laboratory rodents: mouse (Mus musculus) and rat (Rattus norvegicus). In: Weiss D. J. and Wardrop K. J. (Eds.), Schalm's Veterinary Hematology, $6^{\text {th }}$ Edition, Wiley-Blackwell, Iowa. P. 852 862.

Colville J. (2002). Blood chemistry. In: Hendrix C.M. (ed) Laboratory procedures for veterinary technicians, $4^{\text {th }}$ edn. Mosby, St Louis, pp. 75-103.

Eze, S.O., Cornelius, C. and Okereke, H.C. (2012). Phytochemical and antimicrobial analysis of the stem bark of Pterocarpus santalinoides (Nturu ukpa). Asian J. Nat. Appl. Sci. 1(3): 26-32.

Harborne, J.B., (1998). Phytochemical methods - A guide to modern techniques of plant analysis. Chapmann and Hall, London. 129 134.

Lorke, D. (1983). A new approach to practical acute toxicity testing. Arch. Toxicol. 53: 75-289.

Odeh, I. C. and Tor-Anyiin, T. A. (2014). Phytochemical and Antimicrobial Evaluation of Leaf-extracts of Pterocarpus santalinoides. Eur. J. Med. Plants 4(1): 105-11.

NRC. (1985). Guides for the Care and Use of Laboratory Animals. National Academic Press, Washington DC, USA.p. 83.

Offor, C.E., Nwankwegu, N.J. ,Ugwu, O. P.C. and. Aja, P.M. (2005). The effects of ethanol leaf-extract of Pterocarpus santalinoides on liver enzymes of albino rats. Amer-
Euras. J. Agric. \& Environ. Sci. 15 (5): 920-922.

Papay J.I., Clines D., Rafi R., Yuen N., Britt S.D. (2009). Drug induced liver injury following positive drug rechallenge. Regul. Toxicol. Pharmacol., 54: 84-90.

Saukkonen, J.J., Cohn, D.L., Jasmer, R.M., Schenker, S., Jereb, J.A. (2006). An Official ATS Statement: Hepatotoxicity of antituberculosis therapy. Am J Respir Crit Care Med., 174:935-952.

Schiff, L. and Schiff, E.R. 1987. Diseases of the liver. $6^{\text {th }}$ ed. J.P. Lippincott, Philadelphia.

Singh, A., Bhat, T.K. \& Sharma, O.P. (2011). Clinical Biochemistry of Hepatotoxicity. J. Clinic Toxicol., S4: 1-19.

Singh, G.S., Goyal, R., Sharma, P.L. (2012). Pharmacological potential of silymarin in combination with hepatoprotective plants against experimental hepatotoxicity in rats. Asian J Pharm Clin Res., 5(1): $128-133$.

Sun, J., Schnackenberg, L.K., Berger, R.D., (2009). Studies of acetaminophen and metabolites in urine and their correlations with toxicity using metabolomics. Drug Metab. Lett. 3: 130-136.

WHO (2001). The World Health Organis a tion ( W H O) recommended classification of pesticides by hazards and guidelines to classification 20002001, WHO, Geneva.

Willet, K.L., Roth, R.A., Walker, L. (2004). Workshop Overview: hepatotoxicity assessment for botanical dietary supplements. Toxicol. Sci. 79: 4-9.

Received: 1st August, 2017 Accepted: 30th November, 2017 